ISSN electrónico: 1885-5210

DOI: https://doi.org/10.14201/rmc202016e503510

\title{
LA VISIÓN ARTÍSTICA DE LAS PANDEMIAS
}

\section{The Artistic Vision of Pandemics}

Martina ALONSO LAGO

Servicio de Oncología Médica. Hospital San Pedro. Logroño (España).

Correo electrónico: mmalonso@riojasalud.es

Fecha de recepción: 15 de septiembre de 2020

Fecha de aceptación: 28 de septiembre de 2020

Fecha de publicación: 29 de enero de 2021

\section{Resumen}

Pensamos que la "nueva normalidad" que nos toca vivir por este estado de pandemia es algo muy moderno y excepcional. Hemos buscado en el arte ejemplos de la actitud en otras epidemias, desde la Edad Media hasta nuestros días, y hemos podido constatar que nuestras prácticas actuales ya tienen un referente previo.

Palabras clave: pandemia; arte; pintura.

\section{Abstract}

We think that the "new normal life" that we have to live in this pandemic state is something very modern and exceptional. We have looked for examples of the attitude in art of other epidemics, from the Middle Ages to the present day, and we have been able to verify that our current practices already have a previous reference.

Keywords: pandemic; art; painting.

\section{INTRODUCCIÓN}

Es un buen ejercicio y reflexión, en estos tiempos de pandemia tan atípicos en una vida humana, pero tan comunes a lo largo de la historia, el buscar en el arte las muestras de las nuevas normas y hábitos que hemos de adquirir. En las obras artísticas podemos ver el reflejo de tiempos pasados y su visión, así como las denuncias y homenajes que ahora nos parecen tan actuales. 
No es objetivo de este trabajo el analizar toda la historia del arte en lo referente a pandemias, del cual se podría escribir toda una monografía, sino buscar en el periodo que abarca desde la Baja Edad Media, del arte moderno y contemporáneo ejemplos de lo que ahora nos parece nuevo para nosotros.

\section{EL DESBORDE DE LAS URGENCIAS}

Hemos vivido o por lo menos visto, las imágenes de las urgencias desbordadas, no ya sólo en esta epidemia del COVID-19, sino año tras año en la temporada de la gripe. Los pacientes se acumulan en situaciones penosas y son atendidos como buenamente se puede por todo el personal sanitario. También hemos sido testigos de tener que utilizar incluso pistas de patinaje artístico como morgue por la falta de capacidad de las habituales. Salvando las distancias, traigo a colación la pintura La peste de Asdod (1631) de Nicolás Poussin.

Poussin dota a sus pinturas de contenido moral, y nos presenta una pintura de estilo neoclasicista ${ }^{1}$. El arte neoclásico busca fidelidad a los modelos clásicos, influido por los descubrimientos de la época, Pompeya, Grecia, etc. Se quiere reflejar la grandeza y el heroísmo, con claridad y limpieza de líneas. En este ejemplo, vemos una obra con personajes en distintos planos, y un punto de fuga por la calle central en busca de perspectiva y profundidad. El entorno está representado con edificios clásicos y, en la mitad inferior del cuadro, los personajes nos recuerden un poco a Rafael ${ }^{1}$, gran influencia de Poussin. Presentan un gran dinamismo y movimiento. En él cuadro vemos una ciudad de la antigüedad afectada por una plaga enviada por Yaveh como castigo al robo del Arca de la Alianza. Se puede observar un caos de enfermos, muertos y familiares. También podemos apreciar las ratas responsables de la peste negra correteando, y en el cuello de la mujer muerta representada en escorzo, un bubón característico de esta enfer$\operatorname{medad}^{2}$ (Foto 1 ).

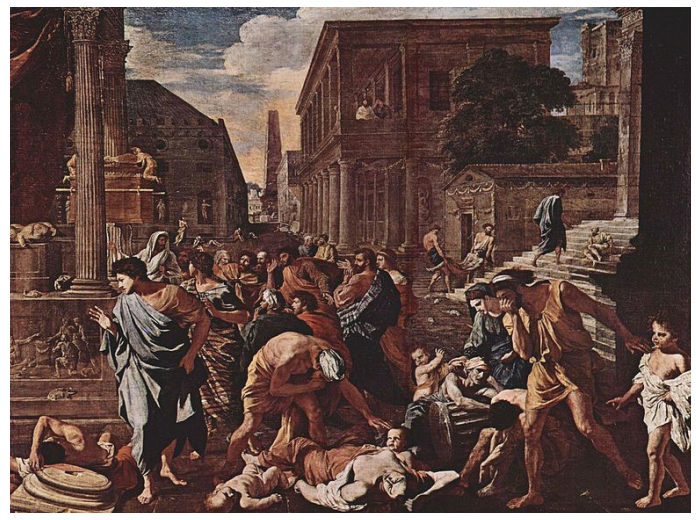

Foto 1. Nicolás Poussin. La peste de Asdod. Óleo sobre lienzo 148 x 198. Museo del Louvre. París.

\section{EL AISLAMIENTO DE LOS ENFERMOS}

El aspecto quizá más duro de las epidemias es el tener que dejar aislados a los enfermos potencialmente contagiosos. Ya en el Decameron de Boccaccio se afirma que basta mirar un enfermo para contraer la peste. Como vemos, la capacidad de contagio y la necesidad de aislamiento ya se conocía ${ }^{3}$ (Foto 2).

Un burgués impide la entrada a la ciudad amurallada de un leproso (con la carraca) y un tullido (con muletas). En esta pintura vemos un ejemplo del arte gótico, en un espacio irreal, plano, sin perspectiva, donde el tamaño de las

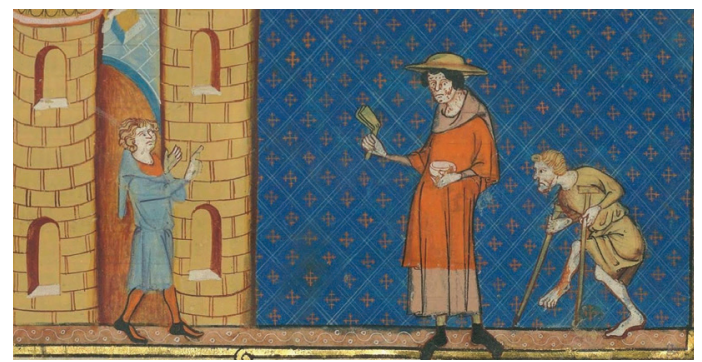

Foto 2. Vicent de Beauvais (c. 1184-1264), Speculum historiale (s. XIV). Bibliothèque de I'Arsenal, folio 373r. 


\section{LA VISIÓN ARTÍSTICA DE LAS PANDEMIAS}

MARTINA ALONSO LAGO

figuras habla más de lo que se quiere destacar que de proporcionalidad. Se ve la línea elegante del dibujo y los colores vivos, con muy discretos detalles dorados.

\section{LA HUIDA}

Todos recordamos como a las puertas del confinamiento muchas personas se fueron a sus segundas residencias. No fue una buena idea, pero la huida de la enfermedad ha existido siempre, lo vemos de nuevo en el Decameron de Bocaccio, algunas personas se van de la ciudad para aislarse en una villa, donde se entretienen contándose historias picarescas ${ }^{3}$. Como ejemplo la imagen de Emigración de los habitantes de la Barceloneta con motivo de la fiebre amarilla por Ramón Padró Pedret (1838-1915) y Tomás Carlos Capuz (1834-1899)4.

Vemos una lámina que posiblemente por los trazos que se aprecian esté hecha a plumilla. Estamos en el siglo XIX, siglo del romanticismo donde la representación de los sentimientos, las atmósferas y la naturaleza alcanzan un gran esplendor. Por otro lado, aunque un poco más tardío y como reacción a la Revolución Industrial y deshumanización de las máquinas surge el realismo, movimiento prácticamente contrario que denuncia la situación real y descarnada que viven muchas personas (Foto 3).

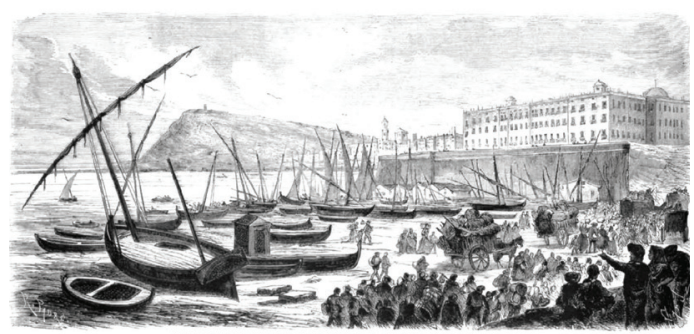

Foto 3. La llustración española y americana. Año XIV. Núm. 26, noviembre 15 de 1870.

\section{EL TRATAMIENTO DE LOS CADÁVERES}

Una de las cosas más duras que hemos visto durante nuestra actual pandemia ha sido el hecho de tener aislados a los enfermos y, como consecuencia, los fallecimientos de los pacientes graves en soledad (en cuanto a la familia se refiere). El tratamiento de los cadáveres ha sido muy escrupuloso con funerales muy limitados de aforo. Como ejemplo artístico presentamos a la Madonna de la Misericordia (1464) por Benedetto Bonfigli².

Estamos en el Quattrocento, en el Renacimiento, aunque en esta pintura de Benedetto Bonfigli encontramos más rasgos del gótico, como el uso de dorados en su pintura y en el fondo, así como en las líneas de su dibujo. No hay perspectiva y el tamaño de los personajes viene dado por su relevancia. Con figuras con poco volumen. Vemos la importancia de la virgen en su mayor tamaño y como abre su manto para protección de la población. A los pies, se lleva a cabo una lucha entre la muerte en forma de esqueleto alado y un ángel protector, con los cadáveres extramuros de la ciudad (Foto 4).

\section{LOS EQUIPOS DE PROTECCIÓN INDIVIDUAL (EPI)}

Protagonismo especial han tenido los EPI durante nuestra actual pandemia, la escasez de ellos en un primer momento hizo que los profesionales pasaran grandes apuros y acudieran a fabricaciones caseras para capear el temporal.

Ya podemos ver en alguna ilustración del siglo XVII que el galeno llevaba una vestimenta de protección y una mascarilla que ha servido de inspiración a muchas máscaras venecianas. La ilustración de Pulus Fürst (1656) muestra el traje diseñado por el médico de Luis XIII para la epidemia de Marsella. Se trata de un dibujo, en blanco y negro, aclarativo y de líneas sencillas. En la máscara se introducían hierbas aromáticas 


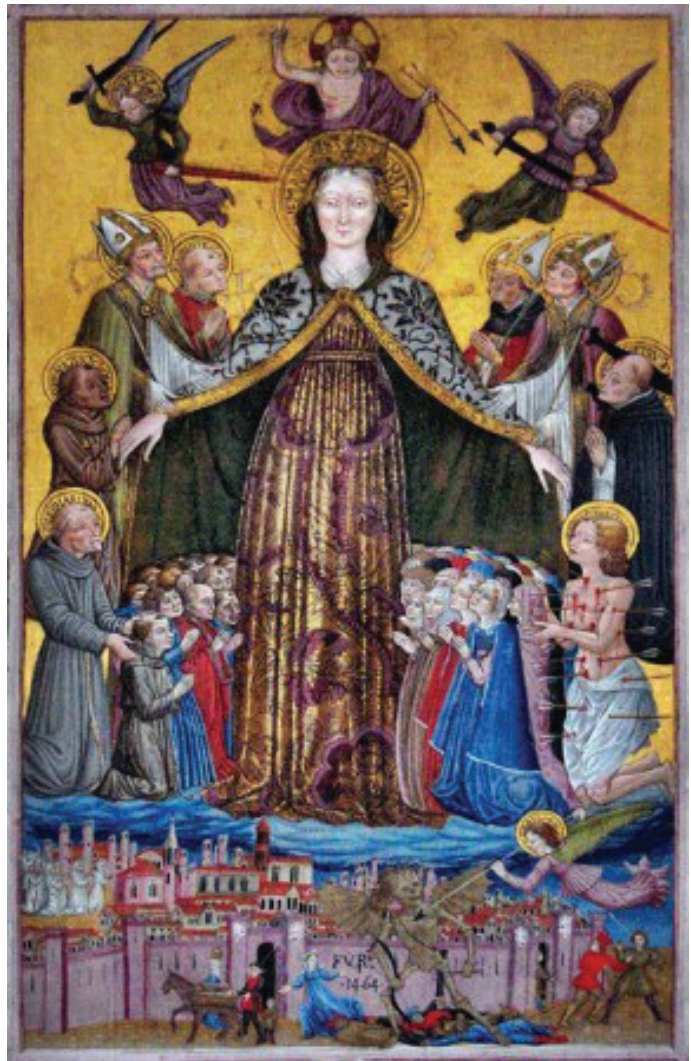

Foto 4. Benedetto Bonfigli. (1464) Madonna de la Misericordia. Oratorio de San Bernadino, Perugia.

y perfumes para sobrellevar la fetidez de los enfermos. El bastón debían llevarlo todos aquellos que tuviesen contacto con los enfermos ${ }^{2}$ (Foto 5).

\section{LAS MASCARILLAS}

Se han hecho habituales en nuestro atuendo diario, pero al principio de la pandemia la escasez de estas hizo que muchas personas se las ingeniasen para hacerlas caseras, apareciendo recomendaciones y tutoriales en internet. Como vemos esto no es nuevo, ya en el siglo XIX las clases populares altas

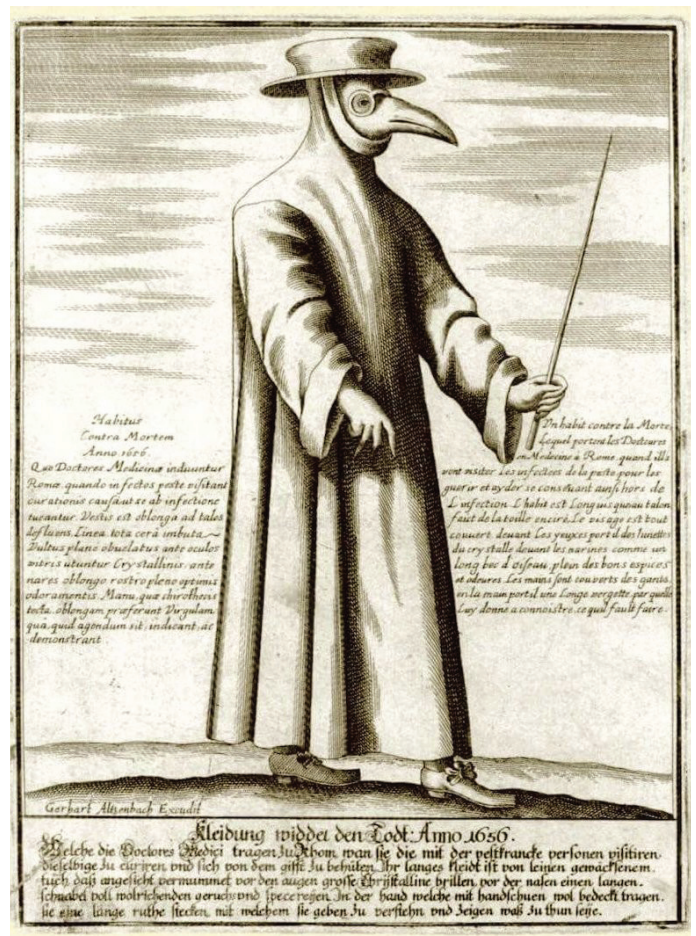

Foto 5. Paulus Fürst, (1656). Atuendo de Medico.

huían con la protección que podían. En esta caricatura, se ve a una familia que las lleva posiblemente de mimbre ${ }^{4}$.

En las caricaturas se busca un tono humorístico exagerando aquellos rasgos más representativos para llamar la atención sobre algún aspecto en particular. Ya desde la Antigüedad se usaba y es un recurso que se ha mantenido hasta nuestros días ${ }^{5}$ (Foto 6 ).

\section{EL HEROÍSMO DE LOS SANITARIOS}

Las profesiones sanitarias suponen momentos de renuncia a la seguridad propia por la ayuda al prójimo. Nos han quedado ejemplos de la valentía de los médicos franceses ante la fiebre amarilla de 1821 en Barcelona ${ }^{6}$. En el grabado se ve al Dr. Mazet auxiliando a un enfermo, este médico 


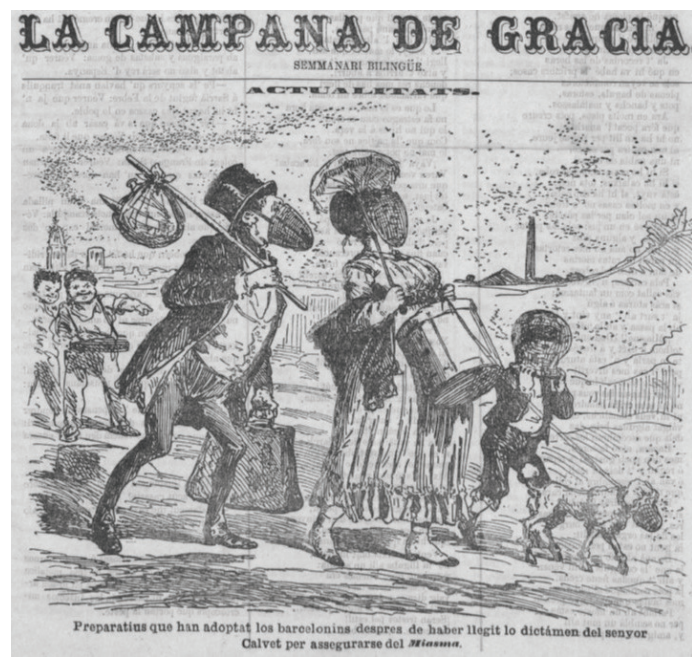

Foto 6. La Campana de Gracia - Any I Batallada XXIII - 9 de octubre de 1870.

fallecerá contagiado. Vemos los rasgos románticos de exaltación del héroe, de los sentimientos y del hombre, se da valor a los marginados. También podemos apreciar la iglesia al fondo con algunos rasgos góticos (los románticos expresan gusto por su pasado, por lo medieval y por las ruinas nostálgicas en sus dibujos y pinturas) (Foto 7).

Dentro del street art podemos admirar la obra de nuestro contemporáneo Banksy. Un niño juega con una muñeca enfermera con capa de heroína, la única nota de color la presenta la enfermera en la cruz roja que aclara a que se dedica. Banksy suele combinar aspectos contradictorios en sus grafitis que dejan perplejo al espectador y le hacen detenerse y reflexionar. Su arte defiende la justicia, el ecologismo y la solidaridad, por otro lado, denuncia las injusticias, la falta de conciencia y el capitalismo (Foto 8).

\section{LA SOLIDARIDAD}

También hemos visto como han surgido manos amigas que han acercado la compra a aquellos que

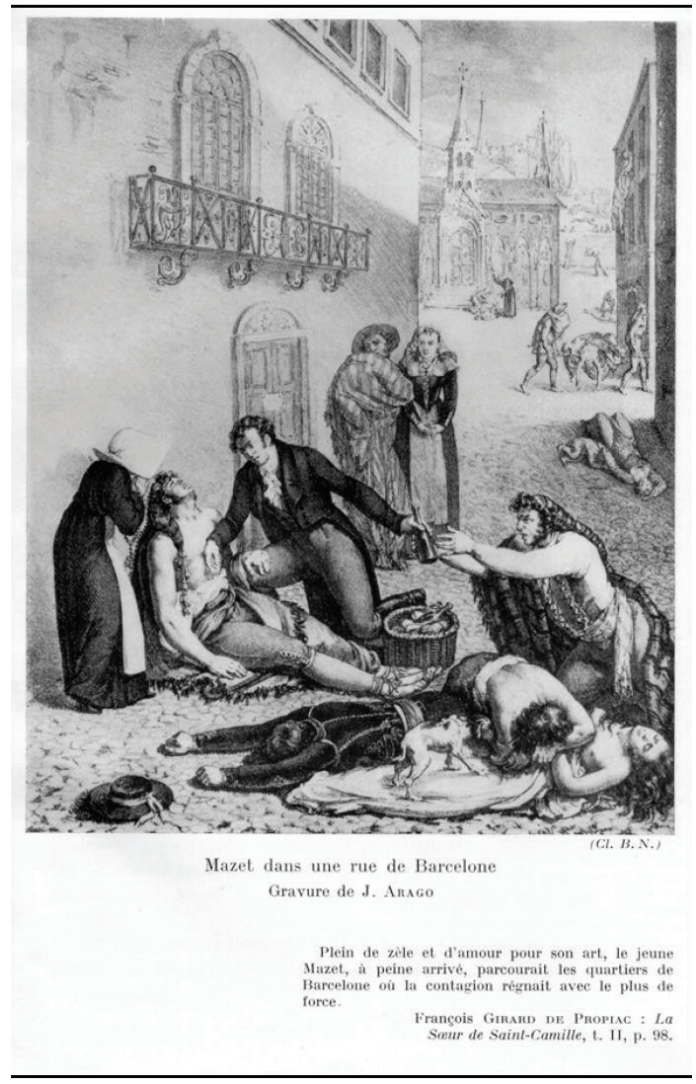

Foto 7. Grabado de J. Arago. Mazet en una calle de Barcelona.

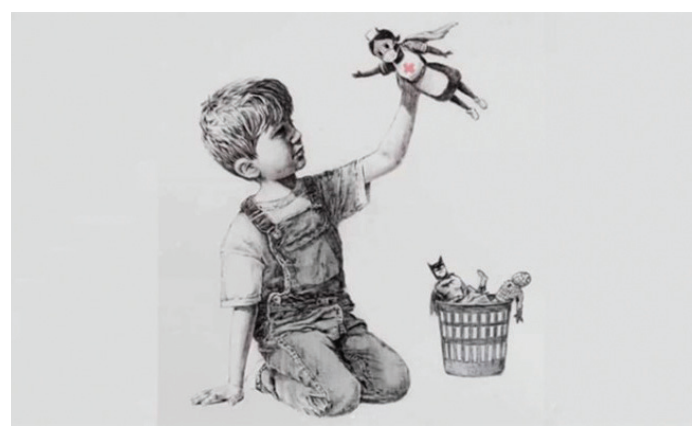

Foto 8. Banksy. Grafiti homenaje a los sanitarios. 
no podían salir o, se han ofrecido a otras tareas para ayudar a aquellos más vulnerables.

Estamos ante una obra de Goya del Romanticismo temprano, no interesa la razón, sino el hombre, sus sentimientos, lo pesimista y lo siniestro que logra creando una atmósfera inquietante y brumosa, con la iluminación que llega desde la ventana de atrás, dejando las zonas más próximas en sombra. Pero la grandeza de Goya viene por ser un adelantado a su tiempo por su Impresionismo en una pintura poco definida, Expresionismo en su dramatismo y Surrealismo por una imagen que parece soñada ${ }^{7}$ (Foto 9).

El escultor Pepe Espaliú enfermo de SIDA realizó una performance Carrying en la que con los pies descalzos era transportado de unos brazos a otros por las calles de Córdoba ${ }^{8}$. Este tipo de performances forman parte del arte contemporáneo actual desde los años 50, en los que el artista utiliza su propio cuerpo para expresarse y realiza una serie de acciones que llevan a reflexionar al espectador. Dado su carácter efímero necesitan ser documentadas con video o fotografía (Foto 10).

\section{LA PROPAGANDA POLÍTICA}

En los momentos duros es cuando nuestros políticos deben demostrar estar a la altura. Lo

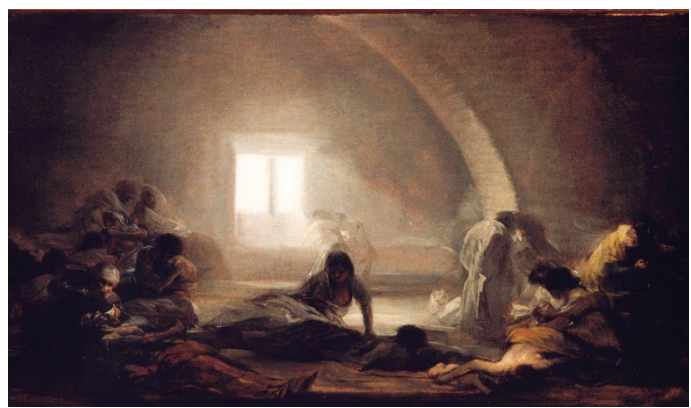

Foto 9. Francisco de Goya. Hospital de apestados. 1808-1810. Óleo sobre lienzo. 32,5 $x$ 57,3 cm. Colección Marqués de la Romana, Madrid, España.

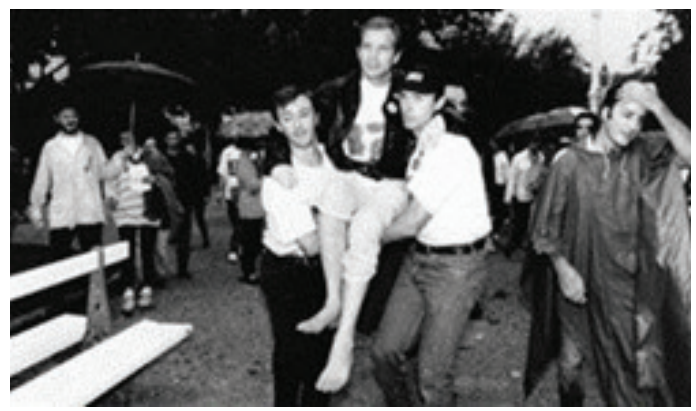

Foto 10. Documentación fotográfica del «Carriying» de Espaliú de 1992. Extraído del periódico $A B C$.

harán con mayor o menor acierto, pero lo que es claro que intentarán sacar rédito político.

En esta pintura vemos a Napoleón rodeado de apestados tocando el bubón de uno de ellos en un gesto de gran valentía ${ }^{9}$. Así, nuestros políticos se han hecho fotos en hospitales de campaña improvisados o han intentado salir en todos los medios disponibles como parte importante de la solución (Foto 11).

Volvemos a ver el heroísmo, la importancia del hombre y sus penalidades y el ambiente arquitectónico y atmosférico propio del romanticismo.

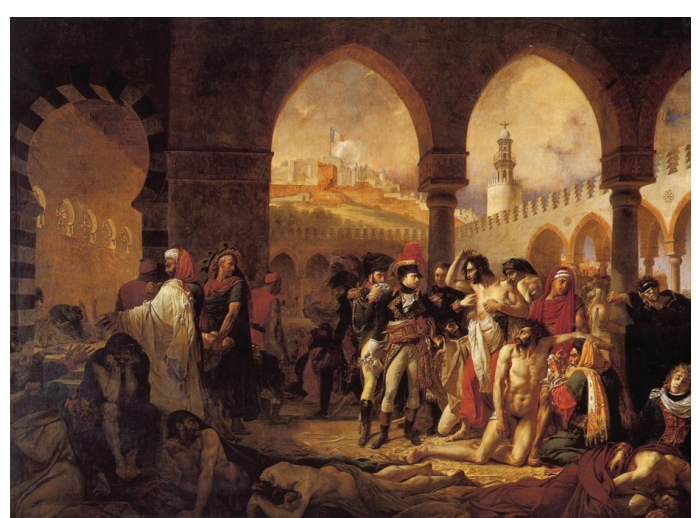

Foto 11. Antoine Jean Gros. 1771-1835. "Visita de Napoleón a los apestado en Jaffa". 1804. Óleo sobre lienzo. $523 \times 715 \mathrm{~cm}$ Museo del Louvre, París. 


\section{LA CORRIENTE NEGACIONISTA}

El miedo o la ignorancia a veces nos hacen negar la evidencia. La epidemia de COVID-19 no se ha librado de aquellos charlatanes que piensan en ella como maniobra de distintos poderes para manipular a la población. Es curioso como los bulos se hacen "virales" y hay personas que dan credibilidad a las teorías más extrañas sobre tratamientos y conspiraciones. En la historia ha habido momentos en los que la información se ha censurado, como en la llamada "gripe española" que adquirió este calificativo porque fue la prensa de nuestro país la primera en hablar sobre ella, ya que en 1918 España no participaba en la Primera Guerra Mundial y no existía el problema de minar la moral de las tropas, que por otro lado fueron las que favorecieron la rápida diseminación de la enfermedad con una mortalidad que llegó a casi los 40 millones de personas. En otras ocasiones la sociedad ha querido mirar hacia otro lado como en la epidemia del SIDA, estigmatizando la población homosexual, la prostitución y la drogadicción. Las siluetas de Keith Haring que falleció de SIDA, hacen alusión a la ignorancia, el miedo y el silencioº Forma parte de nuestro arte contemporáneo o street art utilizando los grafitis como denuncia. Podemos ver la sencillez, incluso el infantilismo que muestran muchas obras del postmodernismo (Foto 12).

\section{LA SENSIBILIZACIÓN CIUDADANA}

En el otro extremo, hemos protagonizado escenas de aliento y apoyo popular hacia todas aquellas personas que de una forma $u$ otra estaban luchando con la enfermedad o procurando apoyo y alimento a la población. Ha sido una imagen habitual los aplausos en los balcones a las ocho de la tarde y las amenizaciones musicales que algunos vecinos han improvisado. Todo ello ha dado lugar distintas exposiciones

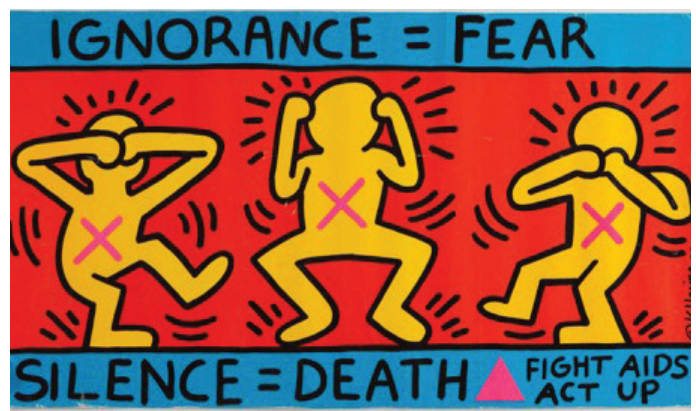

Foto 12. Keith Haring. Grafiti denuncia del rechazo y el miedo al SIDA.

fotográficas, que son un magnífico ejemplo de nuestro arte contemporáneo. La fotografía ha pasado de ser algo que se hacía una o dos veces en la vida hace dos o tres generaciones, a un medio de masas presente prácticamente casi todos los días en nuestras vidas, de ahí que su trivialización haga que cada vez más personas busquen el lado artístico de las mismas y sea complicado y confuso encontrar la buena calidad.

De nuevo el Street art con Keith Haring nos muestra este otro lado más solidario en algunos de sus grafitis, de líneas sencillas y un poco naive (Foto 13).

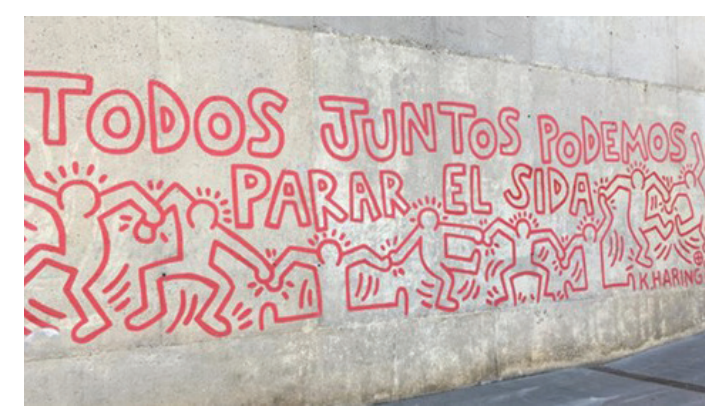

Foto 13. Keith Haring. Grafiti que muestra la necesidad de solidaridad con el SIDA. 


\section{LA VISIÓN ARTÍSTICA DE LAS PANDEMIAS \\ MARTINA ALONSO LAGO}

\section{REFERENCIAS}

1. Poussin N. Museo del Prado. [Internet]. [Consultado el 5 de sptiembre de 2020].

2. Muñoz, M. Arte y Pandemia, una Revisión Histórica. En Chromart Magazine. [Internet]. [Consultado el 18 de agosto de 2020].

3. Ledermann DW. El hombre y sus epidemias a través de la historia. Rev Chil Infect.2003; 20(supl): 13-17.

4. Ortiz JA. Autoridad e imagen de la epidemia: la fiebre amarilla en la Barcelona del siglo XIX. Potestas: Religión, poder y monarquía. Potestas. 2017; 11(5): 93-110.

5. Peláez Malagón JE. Proyecto Clío. Historia de la caricatura. [Internet]. junio de 2002. [Consultado el 9 de septiembre de 2020].
6. Tremblay J. Léon François Hoffmann, La peste à Barcelone. En Marge de l'histoire politique et littéraire de la france sous la restauration. Princeton:, Université De Princeton Dépt. De Langues Romanes; 1964.

7. Fundación Goya en Aragón. Hospital de apestados. [Internet]. 28 de julio de 2017. [Consultado el 18 de agosto de 2020].

8. Alcaide J. Pepe Espaliú y el "carrying" que merecemos. ABC [Internet]. 3 de junio de 2020. [Consultado el 18 de agosto de 2020].

9. Fundación IO. Visita de Napoleón a los apestados en Jaffa. [Internet]. 7 de febrero de 2019. [Consultado el 18 de agosto de 2020].

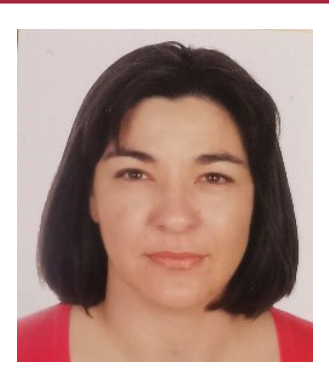

Martina Alonso Lago. Licenciada en Medicina y Cirugía. Universidad de Zaragoza. Graduada en Humanidades por la UNIR. Universidad Internacional de La Rioja. Médico Interno Residente en Servicio de Oncología Médica del Hospital Clínico Universitario de Zaragoza (1993-1997). Título de especialista en Oncología Médica. Hasta 2002: Oncólogo Médico en el Hospital de Barbastro. Desde el 26 de Agosto del 2002 hasta la actualidad: Oncólogo Médico en el Hospital San Pedro de Logroño. Participo de la docencia postgrado del Hospital San Pedro desde Octubre de 2008 hasta la actualidad. Varias publicaciones en libros y revistas científicas. 